\title{
The acquisition of bar press avoidance as a function of shock intensity'
}

ROBERT C. BOLLES AND JOHN A. WARREN, JR. ${ }^{2}$

HOLLINS COLLEGE

\begin{abstract}
Abstraet
Six groups of Ss were trained in bar press avoidance using shocks of .10, .18, .42, .80, 1.6 or $2.2 \mathrm{ma}$. Except for the $.10 \mathrm{ma}$ Ss, who performed poorly because such weak shocks failed to maintain their escape behavior, performance was negatively correlated with the shock intensity.
\end{abstract}

\section{Introduction}

It has been noted that the acquisition of avoidance proceeds much more slowly and uncertainly in the bar press situation than it does in the shuttle box (e.g., Meyer et al, 1960). But we know little about the identity or operation of the experimental variables that produce this difference. One of the contributing factors may well be the indirect effects in the two situations of S's shock-produced activity level. On the assumption that activity level increases with shock intensity, it might be expected that while avoidance acquisition improves with shock intensity in the shuttle box (Brush, 1957), it would be impaired by increasing shock intensity in the bar press situation. The present study tests this hypothesis.

\section{Method}

The Ss were 72 female naive Sprague-Dawley rats, approximately $3 \mathrm{mo}$. old.

The operant conditioning box was a Foringer model $1102 \mathrm{M}$. The bar required a movement of about 1 $\mathrm{mm}$, or a force of $15 \mathrm{~g}$ 。 to register a response; each response produced feed-back by activating an empty pellet dispenser. Timing and programming apparatus was transistorized. The CS was a white noise of approximately $75 \mathrm{db}$ produced through the indigenous speaker in the Foringer box. A "constant current" shock was produced by a 900 VDC source and different limiting resistors to give short-circuit currents of $.10, .18, .42, .80,1.6$ and 2.2 ma for different groups. A Grason Stadler scrambler was used.

The interval from shock termination to the onset of noise for the next trial was $20 \mathrm{sec}$. and noise onset preceded shock onset by $10 \mathrm{sec}$. A bar press in the presence of the noise alone terminated it and avoided the shock while a bar press in the presence of both shock and noise terminated both. Ss were randomly assigned 12 to a group (except that two Ss who should have been in the .10 ma group were run under the .18 ma condition). Ss were run in a single session of 200 trials. Most Ss were given no prior "shaping" of the response, but some shaping of the shock-escape response was necessary for about half of the Ss in the $.18 \mathrm{ma}$ and $.10 \mathrm{ma}$ groups. However, none of the

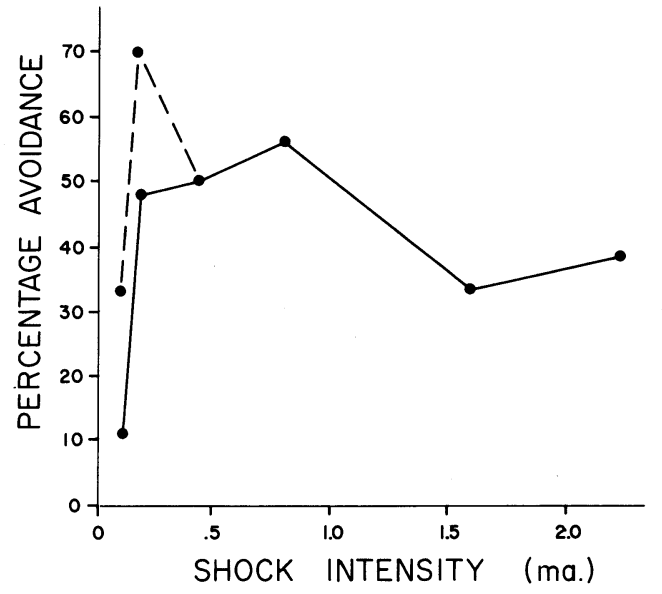

Fig. 1. Median percentage of avoidances during the second 100 training trials as a function of shock intensity. The solid line gives performance of the whole groups; the broken line gives the performance just of those Ss that acquired the escape response,

Ss who ultimately learned the escape response were shaped on more than four trials.

Results

Figure 1 gives the median percentage of avoidances during the last 100 trials for the different shock intensity groups. Group performance (the solid line) was hurt by the 5 out of $10.10 \mathrm{ma}$ Ss and 3 out of 14 $.18 \mathrm{ma}$ Ss who failed to acquire consistent shockescape behavior. Discounting these Ss, or counting just Ss who did acquire good escape behavior, the median avoidance performance is given by the broken line. Counting these "escapers," the .18 ma group was significantly superior (Mann-Whitney test, $p<.05$ ) to the two highest intensity groups, and the .10 ma group was significantly poorer than all other groups. It appears that avoidance acquisition improves with decreasing shock intensity down to the point at which the shock no longer maintains shock-escape responses.

\section{Diseussion}

The failure of some Ss to escape the low intensity shocks is not surprising. By making good contact with the floor $\mathrm{S}$ can minimize its resistance; then, even though current is constant, other parameters of the shock such as voltage drop across $S$ and power dissipation in $S$ are reduced. At sufficiently low current values the rat may be able to reduce the effective shock to below threshold-provided $\mathrm{S}$ does not move. Any movement under these conditions increases resistance and these effective shock parameters and, in effect, becomes self-punishing. It is 
therefore difficult with some Ss to shape up the bar press response initially, and in a few Ss freezing on the floor came to replace bar pressing even after the latter had been established.

In addition to this effect, there appears to be an intrinsic relationship between shock intensity and gross body activity (Kimble, 1955). In the shuttle box a high activity level, whether learned or unlearned, is an advantage to $\mathrm{S}$ since, typically, locomotion is required both for shock termination and for avoidance. However, in the bar press situation, a high activity level is a handicap since $S$ can perform best by remaining at or near the bar. A further difficulty arises in the bar press situation in that if nonlocomotion is conditionable, $\mathrm{S}$ may learn to be too immobile, i.e., freeze on the bar, then $S$ may not be able to make appropriate avoidance responses even though it is still able to make very quick and effective escape responses (Chapman \& Bolles, 1964). In view of the different implications of heightened activity in the two situations it is perhaps not surprising that greater shock intensity, at least up to a point, improves the acquisition of avoidance in the shuttle box (Brush, 1957), but, as we have found, impairs acquisition in the bar press situation.

\section{References}

BRUSH, F. R. The effects of shock intensity on the acquisition and extinction of an avoidance response in dogs. J. comp. physiol. Psychol., 1957, 50, 547-552.

CHAPMAN, J。A., \& BOLLES, R. C. Effect of UCS duration on classical avoidance learning of the bar press response. Psychol. Rep., 1964, 14, 559-563.

KIMBLE, G. A. Shock intensity and avoidance learning. J. comp. physiol. Psychol., 1955, 48, 281-284.

MEYER, D. R., CHO, C., \& WESEMAN, A. S. On problems of conditioning discriminated lever-press avoidance responses. Psychol. Rev., 1960, 67, 224-228.

\section{Notes}

1. This study was supported by Research Grant GB-1650 from the National Science Foundation.

2. Now at McMaster University.
Comment on Kenyon \& Krieckhaus by Irving Zucker

Kenyon \& Krieckhaus (1965) reported that rats with septal lesions were impaired on the acquisition of a oneway Active-Avoidance Response (AAR). On the other hand, Zucker \& McCleary (1964) found that cats with lesions of the septum were not impaired in the acquisition of a one-way AAR. In fact, Zucker (1965) showed that cats with lesions of the septal-limbic area that were deficient in the performance of a passiveavoidance response, acquired a one-way AAR in significantly fewer trials than controls.

The possibility exists that the impaired performance of rats with septal lesions on the one-way AAR is due to the fact that Ss were handled following each trial (Kenyon \& Krieckhaus, 1965; Vanderwolf, 1964). The comparable experiments on the cat, in which no impairments were found, employed an avoidance apparatus which eliminated the handling of Ss between trials (Zucker, 1965)。It should also be noted that in the twoway active-avoidance test, during which Ss presumably were not handled, the performance of rats with septal lesions was superior to that of controls (Kenyon \& Krieckhaus, 1965).

Before assuming that septal lesions differentially affect performance on one and two-way active-avoidance responses, it would appear to be necessary to establish that avoidance learning of rats with septal lesions is not influenced by the handling of Ss during training.

\section{References}

Kenyon. J. \& Kriekhaus, E. E..Decrements in one-way avoidance learning following septal lesions in rats Psychon. Sci., 1965, 3, 113-114

Vanderwolf, C. H Effect of combined medial thalamic and septal lesions on active-avoidance behavior, J. comp. physiol. Psychol., $1964,58,31-37$

Zucker, I \& McCleary, R A. Perseveration in septal cats Psychon. Sci., 1964, 1, 387-388

Zucker. I Effect of lesions of the septal-limbic area on the behavior of cats. J. comp. physiol. Psychol. 1965, in press 